entirely, its consumer protection role being taken over by the new service and its research into the efficacy of medicines to be handed over to branches of NIH.

The past year has not been a happy one for either HEW or the FDA. Both heads have resigned, Mr John Gardner having left the secretaryship when the department was not given increased funds in the face of the most crying social needs. (It is rumoured that he has been offered Robert Kennedy's Senate seat, which is still unfilled.) Yet $\mathrm{Mr}$ Cohen, the new secretary, like Dr Herbert Iey, jun., who succecds Dr Goddard at the FDA, is expected to continue the crusading work of his predecessor, with perhaps more attention to tact. Yet those who expected Mr Cohen, promoted from HEW's ranks, to be as mild in thought as his manner suggests have been rudely surprised. Already the new secretary has proposed (in a speech at Brown University) something which, in American political life, could hardly be more radical: a unified national welfare system of payments to the old, blind, disabled and to dependent children, the size of the cheque to be determined in Washington with little regard for the prevailing local attitudes towards race, laziness, illegitimacy, and other human ills-attitudes which vary picturesquely and arbitrarily from one state to another.

\section{Opinions about Porton}

A NUMBER of eminent people have now publicly expressed their opinions about chemical and biological warfare. Twenty-one fellows of the Royal Society, including eight Nobel laureates, wrote personal letters to the Prime Minister on June 27 asking for all work carried out at the Microbiological Research Establishment at Porton to be published. They are worried about research which leads to the development of offensive weapons. Many scientists apparently believe that this work is indirectly contributing to a stockpiling of offensive biological weapons.

In general, the writers of these letters agree with Mr Tam Dalyell, Labour MP for West Lothian, who considers that the work at MRE should be declassified and the responsibility for research transferred from the Ministry of Defence to a civilian authority. His question to the Prime Minister, asking whether the Government will consider transferring this responsibility to the Ministry of Health, has been postponed for three weeks.

On the same day that the Prime Minister received the letters from the fellows of the Royal Society, eleven members of the Biological Research Advisory Board, which advises MRE on all its activities, wrote to the Times saying that they have full access to all the work at the establishment and are satisfied that it has no military offensive objectives. These eleven scientists, who include Sir Charles Dodds, Sir Ashley Miles and Professor W. J. T. Morgan, are convinced that work is not published only if this involves a risk to national security. They stress that the work carried out at MRE, which as the director has said (Nature, 218,$1114 ; 1968$ ) is concerned with protection against microbiological attack, makes many contributions to medicine, public health and industry. The writers say that statements which contradict this are deplorable and irresponsible.

A similar defence of the Chemical Defence Experimental Establishment at Porton was made by twelve scientists, including Dr J. M. Barnes, Professor R. B. Fisher and Dr D. Tabor, who wrote to the Times on June 26. These scientists said that the establishment and its work, which they know well, is devoted to the protection of Britain from a real threat. They said that no disarmament plan that will work has yet been proposed, and progress is so slow that it may be a very long time before disarmament becomes a reality. Until there is effective disarmament there must be effective protection against chemical attack.

A plea for declassification was made by $\mathrm{Dr} J . H$. Humphrey, who suggested in a letter to the Times on June 29 that a good step towards an attempt to reach an international agreement not to use or manufacture chemical weapons would be for the United Kingdom to show that it does not make or stockpile weapons of this kind. Mr Dalyell has several questions on the House of Commons order paper concerning chemical and biological warfare, and doubtless many more opinions can be expected before there are any signs of official changes.

\section{Change in Medicine}

SHould the medical profession encourage screening as a tool for detecting discase at an early stage ? A World Health Organization publication Principles and Practice of Screening for Disease suggests that screening is not without its snags, and says that the highest rewards will no doubt come from screening of populations in which certain conditions are prevalent and medical care facilities are minimal. Malaria carriers in poorly developed tropical areas are an obvious case. But screening also lends itself to the detection of diseases in developed countries. Anaemia, for one, is particularly suited to screening techniques as are pulmonary tuberculosis, cancer of the cervix and breast and diseases of the eye.

For a disease to be suitable for screening it must be frequent in the population under study, of high morbidity, easily diagnosed by a single sign and there must be a reasonable prospect of cure. Although screening could be carried out by suitably qualified technicians, thereby suving the time of highly trained professional people, in the short term it must add to the doctor's burden as increased detection of disease will lead to greater demand for treatment. Balancing this, however, is the fact that early diagnosis promises better hope of cure and lowers the death rate from malignant disease. In hospitals too, screening of paticnts could lead to a reduction in length of stay, and fewer consultations might be called for. According to the report, the long-term economic aim of screening is to lengthen the productive life of the population, thercby improving the overall economy. But the immediate cost is going to be high and at the moment it looks as though the total cost of screening in a community will be higher than conventional medical care. Nevertheless, the arrival of automation both for carrying out the tests and data processing should lead to a reduction in the cost of sereening.

The report points out that both the medical profession and the public will need to be educated on screening. It suggests that preventive medicine should be taught throughout the medical curriculum and that members of the public should be encouraged to come forward. The report suggests that women should be taught 